\title{
Deep-water Sharks Fisheries off the Portuguese Continental Coast
}

\author{
Ivone Figueiredo and Pedro Bordalo Machado \\ Instituto de Investigação das Pescas e do Mar (IPIMAR) \\ Av. Brasília, 1449-006 Lisboa, Portugal \\ and \\ Leonel Serrano Gordo \\ Faculdade de Ciências de Lisboa (FCUL), Dep. Zoologia e Antropologia e Inst. Oceanografia \\ Bloco C2, Campo Grande, 1749-016 Lisboa, Portugal
}

Figueiredo, I., P. B. Machado, and L. S. Gordo. 2005. Deep-water Sharks Fisheries off the Portuguese Continental Coast . J. Northw. Atl. Fish. Sci., 35: 291-298. doi:10.2960/J.v35.m495

\begin{abstract}
Deep-water sharks represent a major percentage of the total annual elasmobranch landings in mainland Portugal, primarily comprising Portuguese dogfish (Centroscymnus coelolepis), Leaf-scale gulper shark (Centrophorus squamosus) and Gulper shark (Centrophorus granulosus). These species are usually taken as by-catch from fisheries targeting other species. The present work describes the main characteristics of the fisheries for the three species mentioned above that take place mainly from Sesimbra and Peniche. Sesimbra accounts for nearly 50\% of the deep-water sharks landings in mainland Portugal and deep-water sharks constitute a by-catch of the black scabbardfish (Aphanopus carbo) fishery and in Peniche, a by-catch of multispecies artisanal fisheries. The focus was placed on a comparative analysis of the fishing regimes adopted at these two ports.
\end{abstract}

Key words: by-catch, deep-water, Portugal, landings, shark

\section{Introduction}

Sharks are a common by-catch in many of the world's fisheries targeting teleost species. In the past, most shark catches were discarded without being recorded (Walker, 1998). Recently, elasmobranchs, sharks in particular, are becoming more commercially important and their product value has increased accordingly. Worldwide, reported landings of chondrichthyans currently exceed 700000 tons-per-year (Walker, 1998).

In European countries, most shark species are not subject to catch controls and there is therefore no obligation for fishermen to record catches in the logbooks. Moreover, the quality of landings data is also limited due to the lack of species-specific data reported by most countries. In Europe, for example, French bottom trawl catches of deep-water sharks, consisting of Leaf-scale gulper shark (Centrophorus squamosus Bonnaterre, 1788), and Portuguese dogfish (Centroscymnus coelolepis Bocage and Capello 1864) are landed together as "siki" (Anon., 2002).

To properly assess the current state of the shark stocks, to address various problems associated with their exploitation and to contribute new ideas about their management, it is essential to enhance our knowledge of their fisheries, the species that are exploit and the size of the catches (Bonfil, 1994).

The present contribution aims to describe the exploitation by fleets capturing deep-water sharks off the continental Portuguese continental coast. Two Portuguese fishing ports, Sesimbra and Peniche, with major deepwater shark landings are analysed.

\section{Methods}

The main source of data for the study is the landing statistics of Portuguese commercial deep-water shark species, routinely compiled by the General Directorate of Fisheries (DGPA). DGPA is an institution belonging to the Portuguese Ministry of Agriculture, Rural Development and Fisheries.

The Portuguese coast is divided into 5 statistical zones: Norte, Centro, Lisboa e Vale do Tejo, Alentejo and Algarve (Fig. 1). Sesimbra and Peniche, both in the Lisboa and Vale do Tejo zone, were chosen for this study as they are among the major landing sites for deep-water sharks in mainland Portugal, first and fourth most important, respectively. This strategy was followed to investigate 


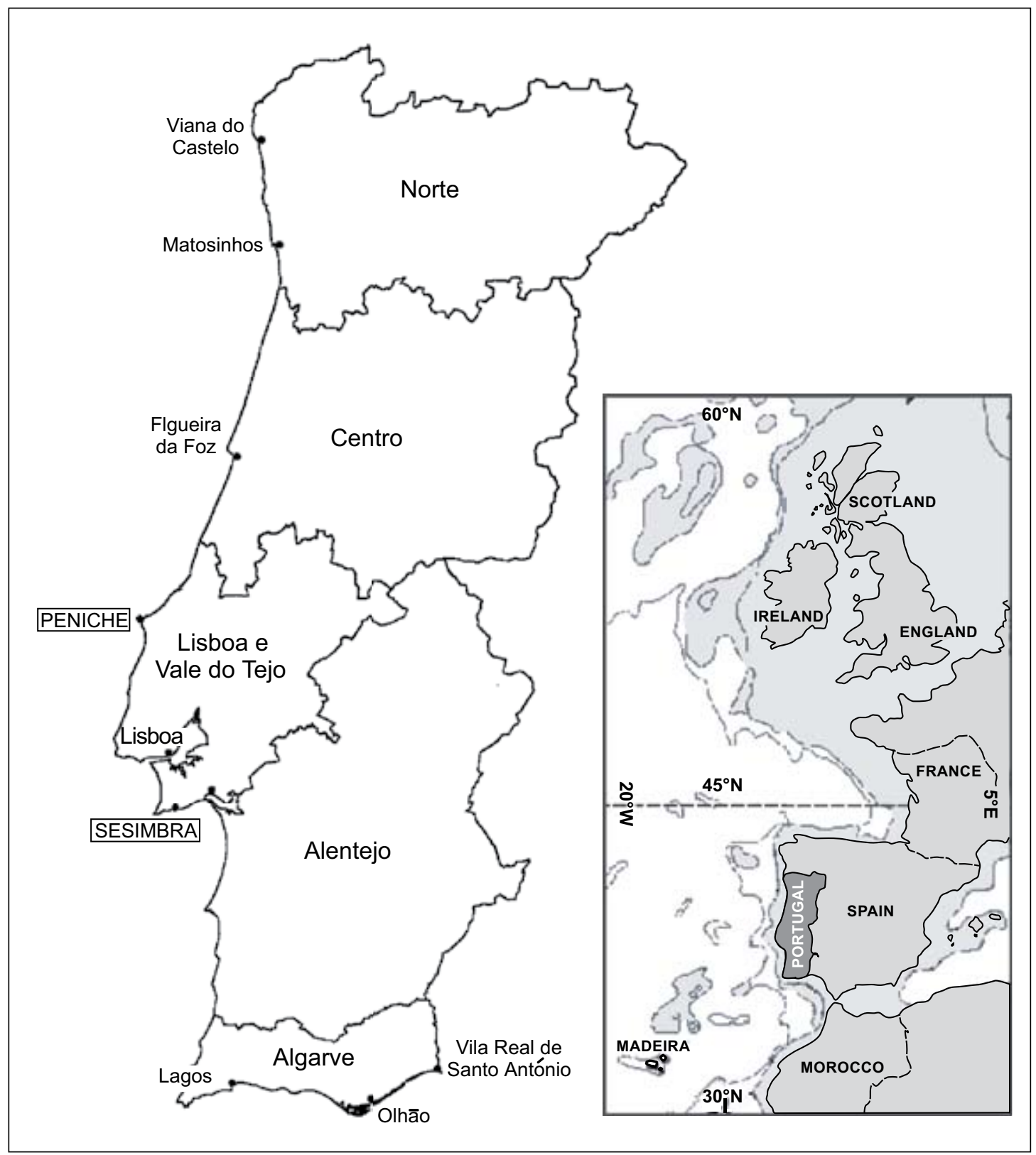

Fig. 1. Mainland Portugal regional zones adopted by the Portuguese Statistical Institute for landing reports. Geographic location of mainland Portugal in Europe.

two distinct fishing realities; Peniche annual landings of deep-water sharks represent in average only $6 \%$ from those of Sesimbra.

\section{Results and Discussion}

Sesimbra is the most important port for deep-water sharks, representing ca. $50 \%$ of the total landings in mainland Portugal (Table 1), Lisboa, Viana do Castelo and Peniche the next important ports. Their fleets, however, have very different characteristics. Peniche has a diversified fleet in which the artisanal fishery represented between 20 and $24 \%$ of the total landings in the last 5 years whereas in Sesimbra, $>70 \%$ of the landings are attributable to the artisanal fleet.

At present, there are no directed fisheries for deepwater sharks off Portugal and therefore, all landings come 
from by-catches of coastal trawl or deep-water fisheries. Coastal, pelagic and deep-water sharks constitute a relatively minor proportion of the total landings of all fishery resources. The great majority $(>60 \%)$ of the vessels land $<25 \%$ of sharks in Peniche and in Sesimbra (Fig. 2). From the same figure, one can also observe the low percentage of vessels that land more than $75 \%$ and this is particularly conspicuous in Sesimbra.
For mainland Portugal, ninety-nine percent of deepwater sharks are caught with longlines (Table 2) at depths ranging from 800 to $1600 \mathrm{~m}$. Between 1992 and 1997, 10000 to 12000 tons were landed annually in Sesimbra while in Peniche the highest landings were in 1994, with $<3000$ tons (Fig. 3). Nevertheless, in both ports, a general decreasing trend was observed since 1992, but with a sharp decrease in 2000. This decrease was much larger in

TABLE 1. Annual landings (tons) of deep-water sharks at the most important landing ports of mainland Portugal.

\begin{tabular}{lrrrrrrrrr}
\hline \hline Landing port & 1992 & 1993 & 1994 & 1995 & 1996 & 1997 & 1998 & 1999 & 2000 \\
\hline Lisboa & 184 & 197 & 187 & 192 & 206 & 144 & 144 & 265 & 130 \\
Peniche & 92 & 74 & 34 & 38 & 48 & 33 & 49 & 82 & 14 \\
Sesimbra & 715 & 579 & 794 & 956 & 850 & 951 & 909 & 1226 & 853 \\
Viana do Castelo & 153 & 130 & 61 & 75 & 59 & 61 & 38 & 103 & 65 \\
Others & 501 & 545 & 575 & 562 & 636 & 654 & 627 & 931 & 647 \\
Total & 1645 & 1525 & 1651 & 1823 & 1799 & 1843 & 1767 & 2607 & 1709 \\
\hline
\end{tabular}

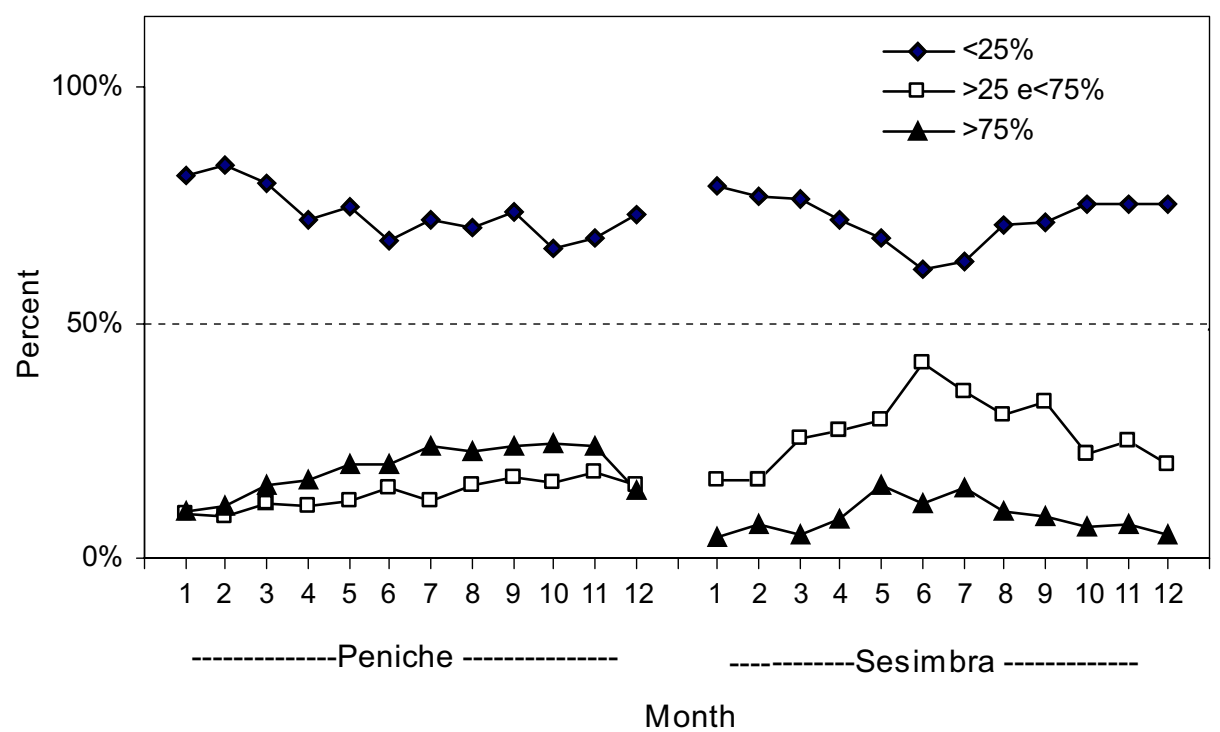

Fig. 2. Percentage of vessels landing sharks by month in Peniche and Sesimbra for the period between 1992 and 2000. Three categories have been distinguished according to the percentage of the total landings consisting of sharks.

TABLE 2. Annual landings (tons) of deep-water sharks by gear from mainland Portugal.

\begin{tabular}{lrrrrrrrrr}
\hline \hline & 1992 & 1993 & 1994 & 1995 & 1996 & 1997 & 1998 & 1999 & 2000 \\
\hline Trawl & 5 & 3 & 3 & 2 & 9 & 8 & 3 & 1 & 4 \\
Longline & 1908 & 1589 & 1359 & 1579 & 1326 & 1631 & 1433 & 698 & 570 \\
Total & 1913 & 1592 & 1362 & 1582 & 1335 & 1639 & 1436 & 699 & 574 \\
\hline
\end{tabular}


Sesimbra (a reduction of ca. 60\%) than in Peniche (30\%), due to closure of the fishery off Morocco.

As far as landings of deep-water sharks are concerned, two different patterns can be seen. Sesimbra shows an increasing trend from 1993 to 1999. In Peniche, landings show a decreasing trend, similar to the one observed for the total landings of all fishery resources in this port (Fig. 3).
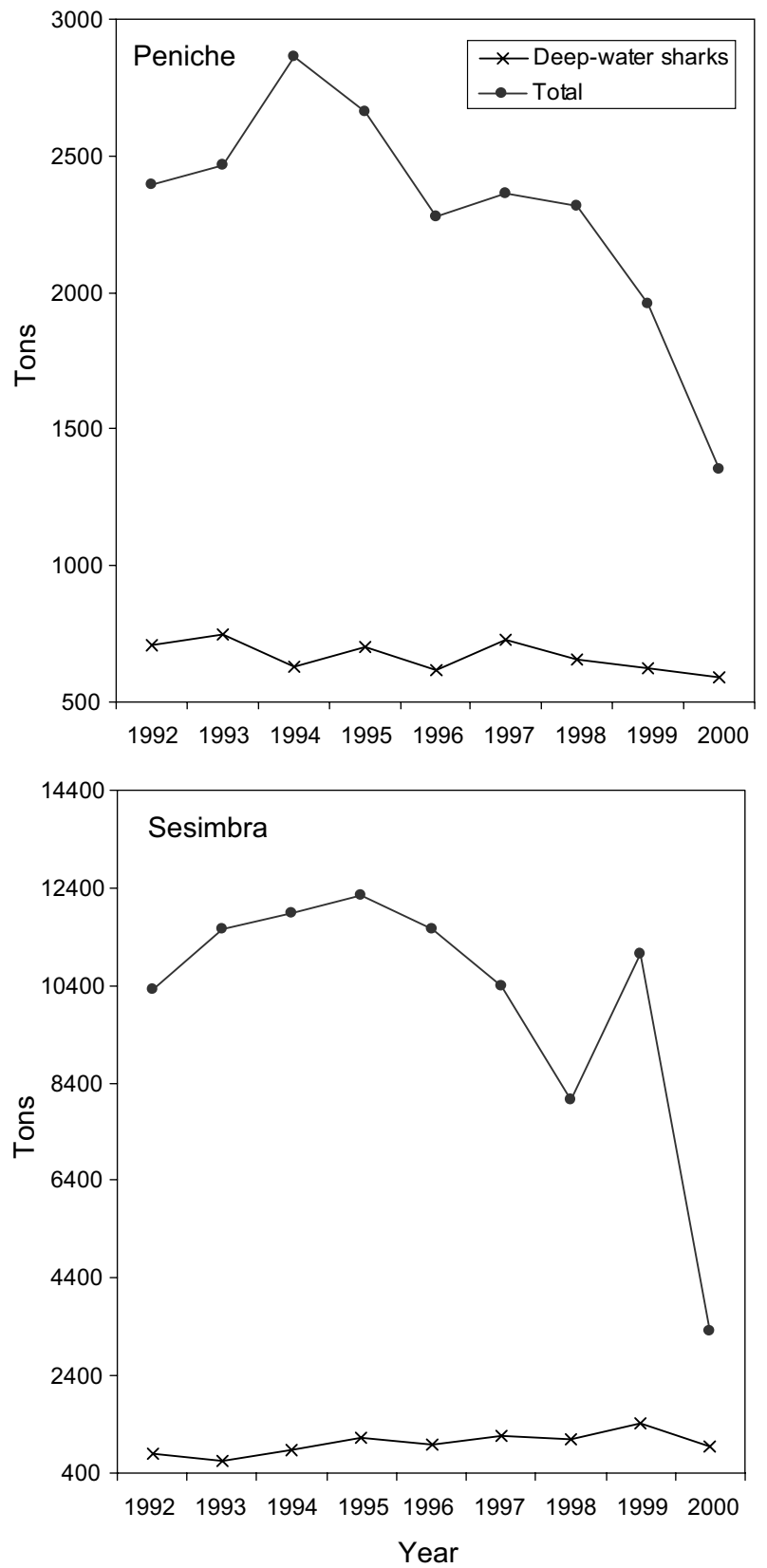

Fig. 3. Deep-water sharks landings versus total landings (tons) in Peniche and Sesimbra between 1992 and 2000.
An analysis of the landings by month also shows different patterns between Peniche and Sesimbra (Fig. 4). In Peniche, a similar trend occurred in both the landings of deep-water sharks and total landings (all species combined) with the highest values obtained between May and July. In Sesimbra, the highest values of deepwater sharks (observed between May and September) corresponded to the lowest value of total landings.
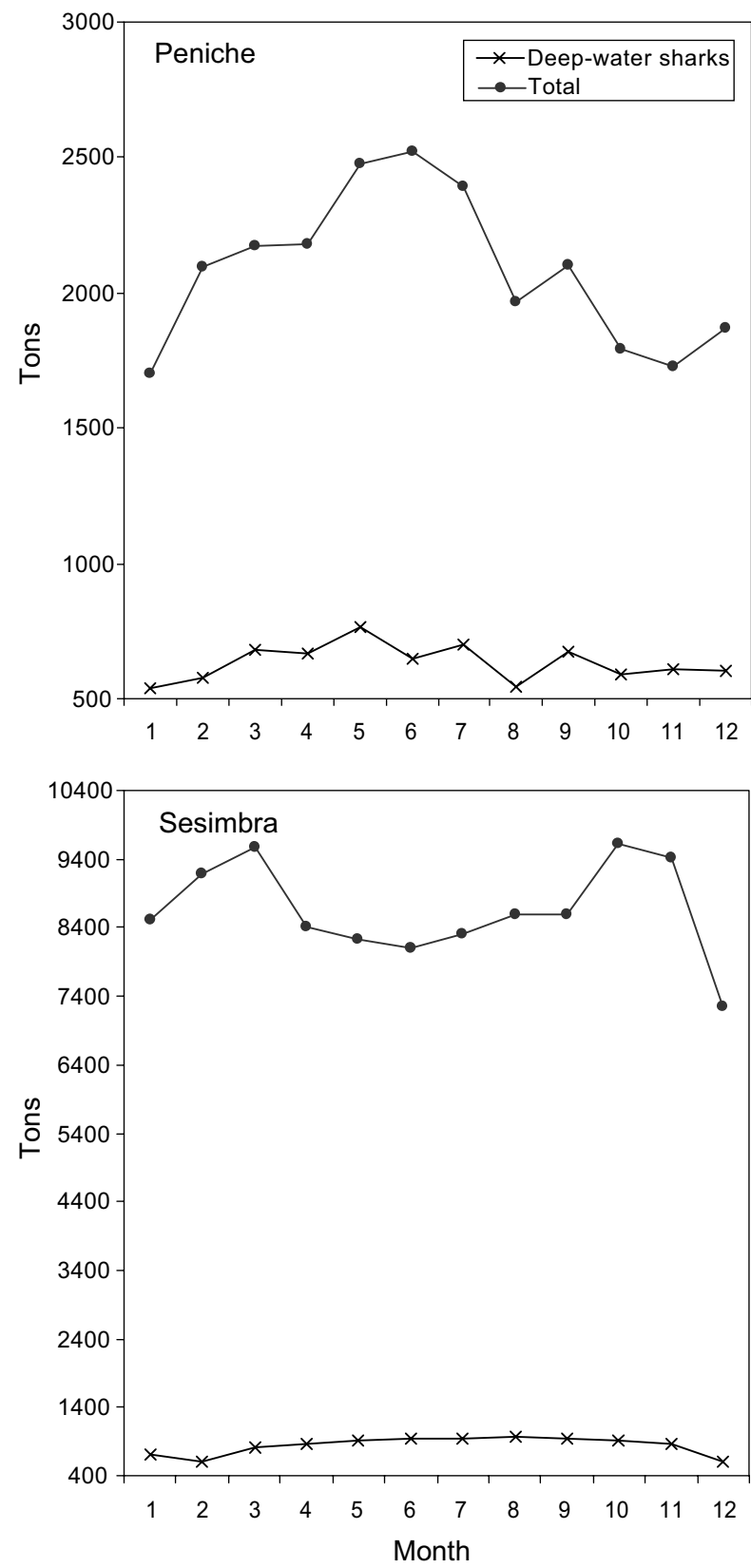

Fig. 4. Monthly landings (tons) of deep-water sharks versus total landings in Peniche and Sesimbra for the period between 1992 and 2000. 
The different temporal patterns on deep-water sharks landings between Peniche and Sesimbra reflect differences in the deep-water fishery. Sesimbra has a larger fleet and more regular activity. This results in a larger annual number of landings of deep-water sharks there (Fig. 5). In Peniche, the pattern of the annual number of landings

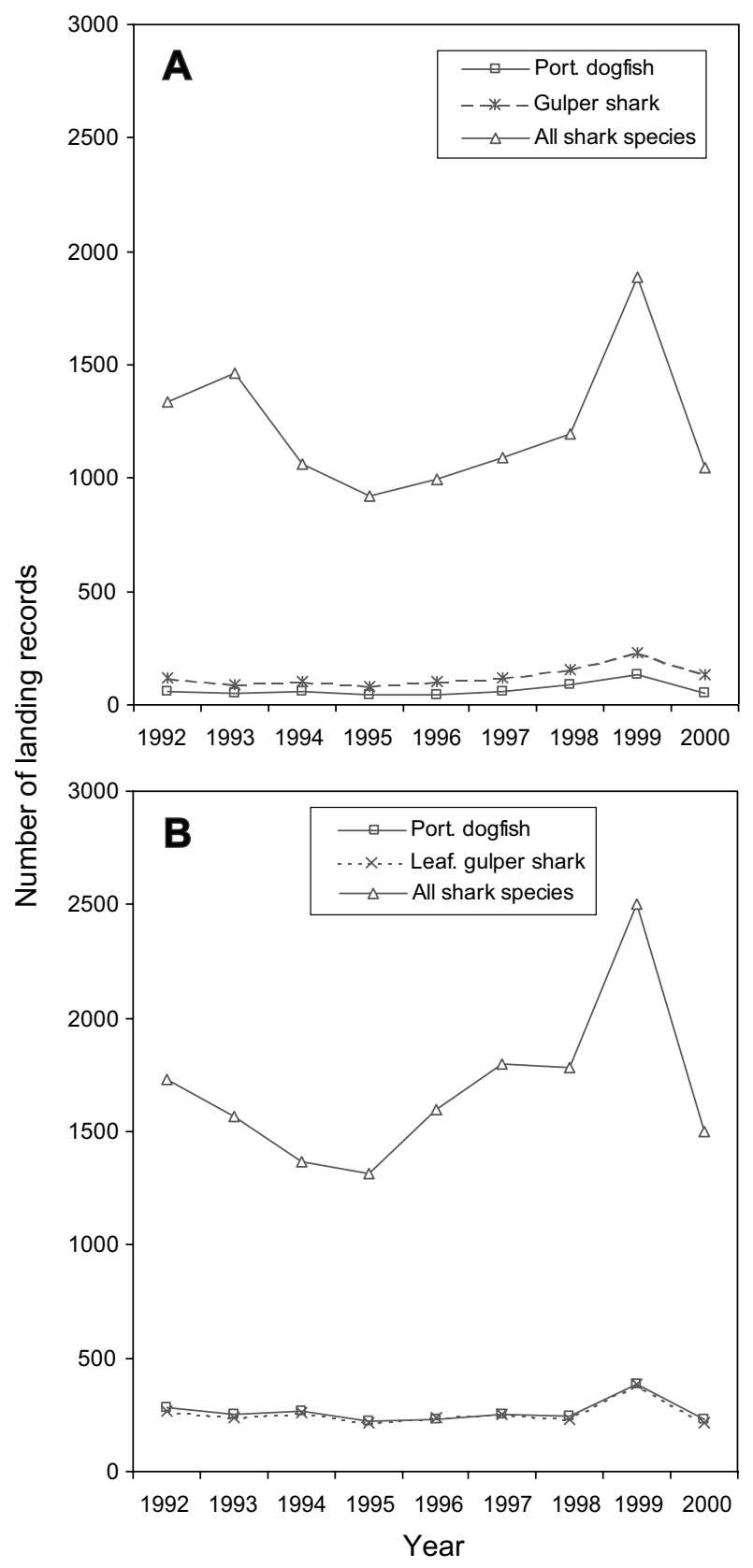

Fig. 5. Number of landing records by year on three deep-water shark species and on all shark species in (A) Peniche and (B) Sesimbra from 1992 to 2000. A landing record corresponds to the total number of landings recorded for each species or category by year. is similar for sharks combined (including coastal, pelagic and deep-water) and for the two most important shark species, Gulper shark; (Centrophorus granulosus Bloch and Schneider, 1801), and Portuguese dogfish. However, the amount of Gulper shark landed is almost twice that of Portuguese dogfish.

In Peniche and Sesimbra, deep-water sharks comprise $>75 \%$ of the total landings of vessels exploiting those species (Fig. 6). Deep-water sharks as a percent of total catch was lower between June and October. Two factors appear to be responsible for the difference between ports. In Sesimbra, the decrease may be related to a lower level of abundance of these species. There is no change in target species - black scabbardfish (Aphanopus carbo). In addition, there is also a decrease in landings of black scabbardfish during the same period (Fig. 7) although there is no reduction in fishing effort. In Peniche, the decrease might be due to a preference to capture other species of higher commercial value. Major quantities of forkbeards (Phycis spp) and European conger (Conger conger Linnaeus, 1758), are landed during late spring and summer (Fig. 8).

Gulper shark, leafscale gulper shark and Portuguese dogfish are the three most important deep-water shark species in terms of total landings. Figure 9 shows the landings of each of these species for the period 19912000. In Peniche, the gulper shark landings are five times greater than the landings of Portuguese dogfish, the second species in ranking. However, the landings of gulper shark show a decreasing trend over time, particularly in 2000, the lowest value in the time series. In Sesimbra, landings of Portuguese dogfish was highest, followed by leafscale gulper shark. Between 1995 and 1999, the landings were slightly higher than the previous period, then decreasing in 2000 to values similar to the ones observed in 1993.

For Peniche gulper shark was highest in commercial value (almost twice the value of the other two species) and an increasing trend in the mean price per $\mathrm{kg}$ is evident from 1991 to 1998 (Fig. 10). For Sesimbra, the leafscale gulper shark has a slightly higher value than the gulper shark and the Portuguese dogfish (Fig. 10).

\section{Conclusions}

A comparative analysis of the two fishing ports Peniche and Sesimbra allowed us to conclude that:

a) landings are attributable mainly to longlines deployed in deep water; the artisanal fishery contributes to the major landings;

b) deep-water sharks are not targets of this fishery; in Sesimbra they are a by-catch of the black scabbardfish 


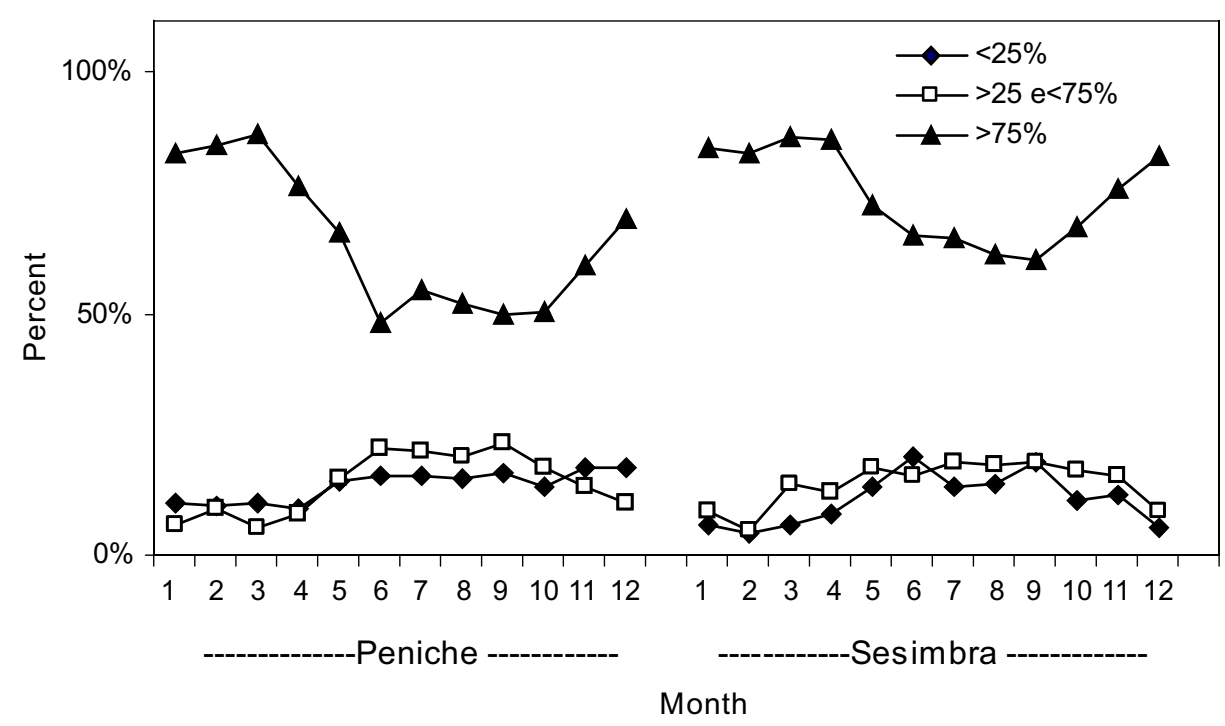

Fig. 6. Percentage of vessels landing deep-water sharks by month in Peniche and Sesimbra in the period between 1992 and 2000. Three categories have been distinguished according to the percentage of the total landings consisting of sharks.

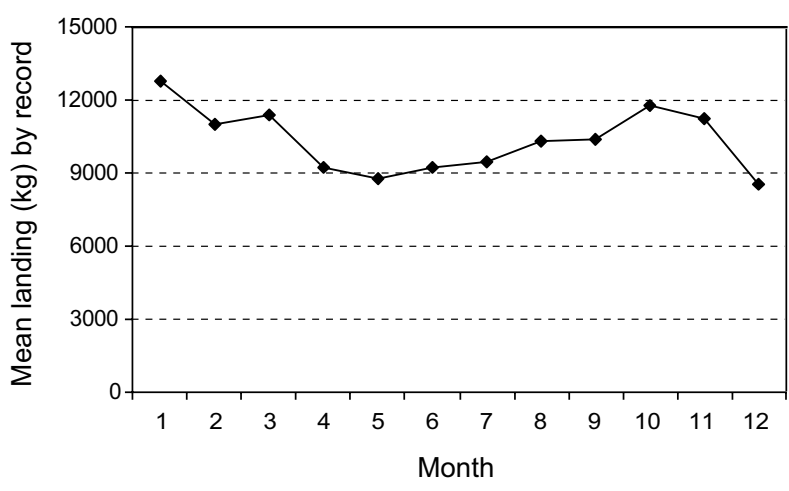

Fig. 7. Monthly mean landings by record of black scabbardfish in Sesimbra between 1992 and 2000.

fishery and in Peniche a by-catch of multispecies artisanal fisheries.

Peniche and Sesimbra represent two distinct realities that result from four issues:

1. Fleet - Peniche has several fleet components (trawl, purse-seine and international fishery), including large and small vessels. Deep-water species landings represent a small fraction, ca. $20 \%$ of overall landings. In Sesimbra, the artisanal longline fleet lands $>70 \%$ of the total landings, mainly by small vessels (8.6 to $22.2 \mathrm{~m}$ overall length and 78 to $272 \mathrm{hp}$ ).

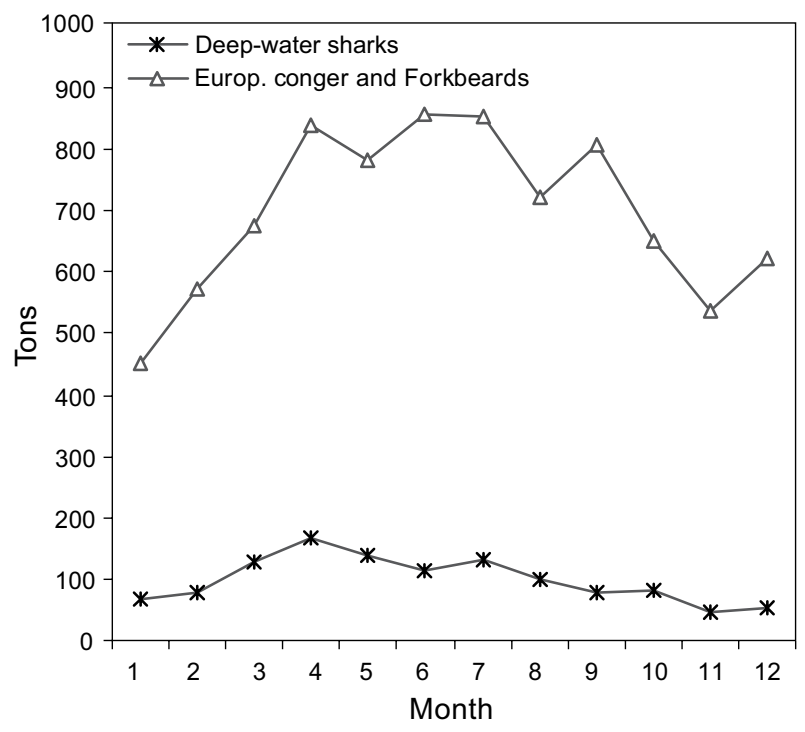

Fig. 8. Landings of forkbeards plus European conger versus deep-water sharks in Peniche by month for the period between 1992 and 2000.

2. Socio-economics - Peniche has a diversified fishery associated with different fishing fleet components. Thus, there are fewer vessels and lower landings in the deep-water fishery compared to Sesimbra. Sesimbra is a traditional, family based fishing community with few technological innovations where the economic, 

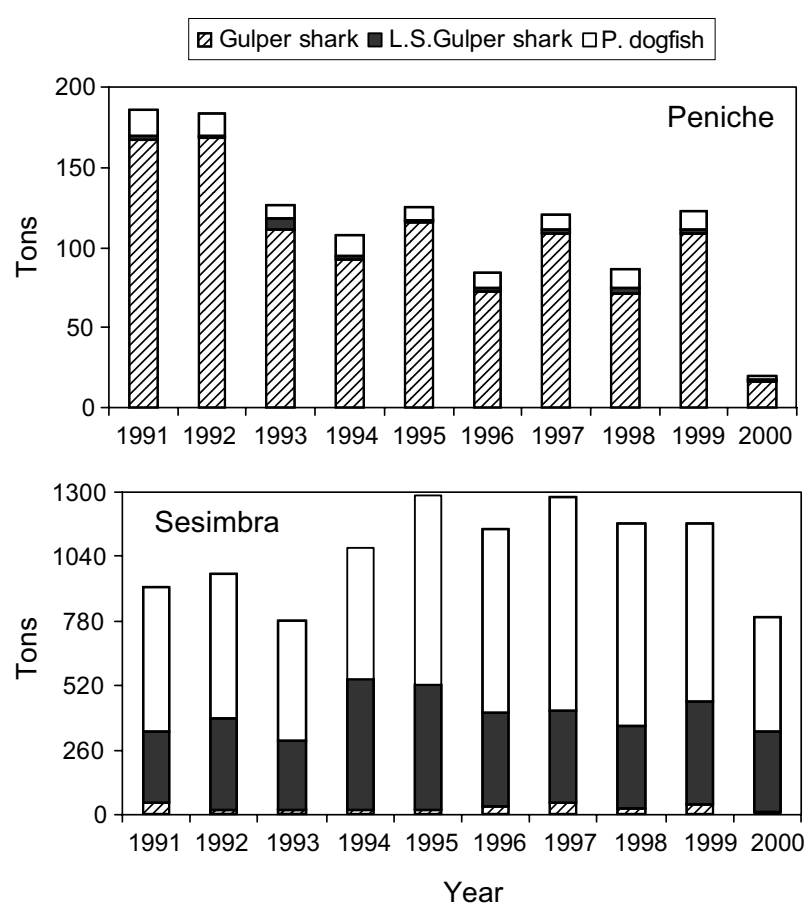

Fig. 9. Landings of Portuguese dogfish, leafscale gulper shark and gulper shark in Peniche and Sesimbra between 1991 and 2000.

social, political and ecological aspects contrast with those found in the highly developed trawl fisheries of northern European countries: e.g. traditional vs modern, artisanal $v s$ industrial, family $v s$ company and conservation $v s$ over-exploitation.

3. Landings - For Peniche, the gulper shark is, by far, the most important deep-water shark landed, followed by the Portuguese dogfish and the leafscale gulper shark. In Sesimbra, Portuguese dogfish is the primary species and secondarily, the leafscale gulper shark. Gulper shark is a minor species.

4. Income - Peniche is a major city and the price of the species per $\mathrm{kg}$ is dependent on supply and demand. From 1991 to 2000, the decreasing trend in landings resulted in an increasing trend in the price of gulper shark. Fewer deep-water sharks of other species are landed but an increase in price occurred in recent

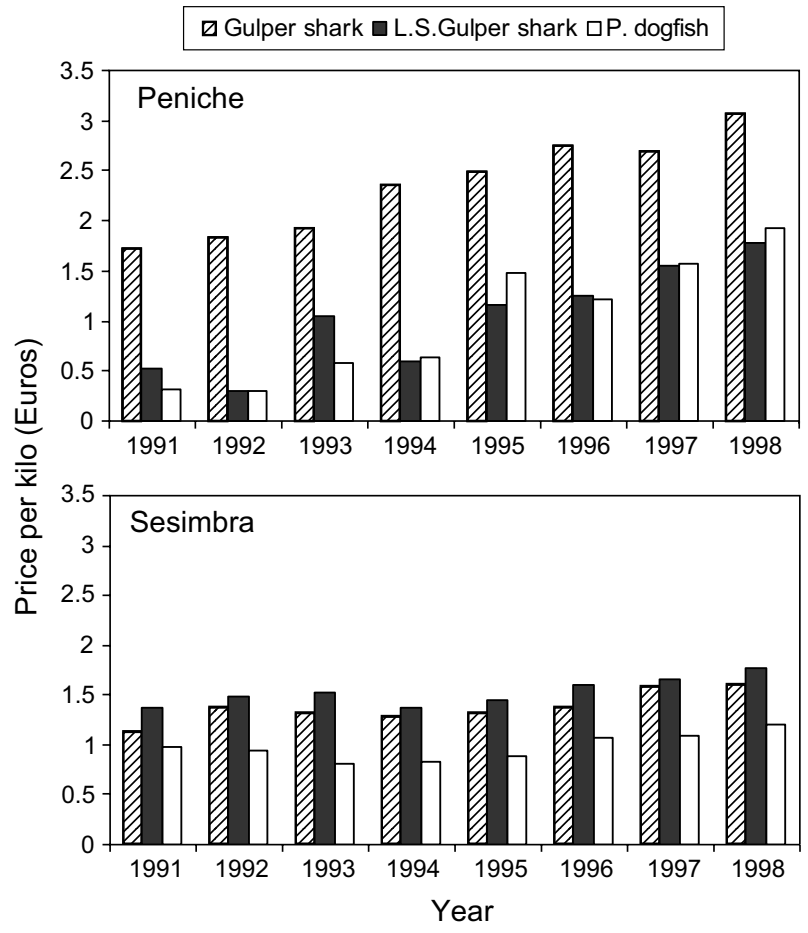

Fig. 10. Annual income values for Portuguese dogfish, Leafscale gulper shark and Gulper shark in Peniche and Sesimbra between 1991 and 1998.

years. In Sesimbra, both landings and prices do not show any marked trend, with the exception of the three deep-water shark species, showing a small increase in price per kilo from 1991 to 2000.

\section{Acknowledgements}

This work was partially funded by Project 22-0501-FDR-00028.

\section{References}

ANON. 2002. Report of the Working Group on the Biology and Assessment of Deep-Sea Fisheries Resources. ICES C. M. Doc., No. ACFM:16, 252 p.

BONFIL, R. 1994. Overview of world elasmobranch fisheries. FAO Fish. Tech. Pap., 341: 119 p.

WALKER, T. I. 1998. Can shark resources be harvested sustainably? Aquestion revisited with a review of shark fisheries. Mar. Freshwater Res., 49: 553-572. 
